\title{
Information Systems Innovation Research: Between Novel Futures and Durable Presents
}

\author{
Margunn Aanestad \\ Department of Informatics, University of Oslo, P.O. Box 1080, \\ Blindern, NO-0316 Oslo, Norway \\ margunn@ifi.uio.no
}

\begin{abstract}
In this paper, I argue that we should not only orient ourselves to the future by looking forward to the yet unrealized. When researching the future, we should also develop a sensibility to the durability of our past and present creations, and understand how they impact the scope for future innovations. The common emphasis on the visionary and novel components of innovation needs to be complemented with an emphasis on the constants, the slowly changing or non-changing aspects. In the paper, I seek to articulate how we could increase our ability to recognize the durability of the present with respect to empirical study objects, analytic approaches, and theoretical resources.
\end{abstract}

Keywords: Innovations, infrastructural inversion, maintenance, installed base.

\section{Introduction: The Durability of the Present}

The call for papers for this conference announced that "it is now time to explore, develop and substantiate the new directions through which our field can shape and influence the future of ICT-based practices. If anticipating and influencing the future is something qualitatively different than immediate research relevance, we must then ask whether and how our approaches to inquiry can affect our ability to do so." In this paper, I will present an argument for researching the future in ways that also pay attention to the role of "durable presents" (Risan 2006).

The dominant way to think about the future in the IS field seems to be to link information and communication technologies (ICT) and innovation. ICTs are often proclaimed to be crucial for the economic growth of nations or regions. This could be directly through the production of innovative ICT solutions for a market, or indirectly in facilitating cost-efficient provision of (public) services through ICT deployment. This coupling between the technology and the wished-for innovation offers an opportunity for IS research to present its research as relevant by contributing to the successful operation of this engine of growth. Such a position entails the risk of sliding into instrumental research, rather than maintaining a questioning and critical position to the legitimacy, purpose, and directions of innovation attempts. A certain pro-innovation bias can be identified both in the IS literature and innovation research 
(Swanson and Ramiller 2004, p. 554). Mainstream IS research on innovation has mainly sought to produce useful knowledge for managers on topics relevant for increased profitability and market share. If we follow Schumpeter's (1934) distinction between invention (making an idea manifest) and innovation (the practical and commercially viable exploitation of an invention), we can say that the managementoriented literature has focused mainly on innovation at the expense of the process of invention. Becoming "innovative" may thus be limited to only deciding to purchase a novel technology or jumping onto a new bandwagon (Fiol and O'Connor 2003; Swanson and Ramiller 2004; ). Typically based on studies of the diffusion of innovations within a population of potential adopters, this research stream has sought to establish either why some organizations are more innovative than others, or what makes certain innovations more adoptable than others (Fichman 2004, p. 317). In more design-oriented research stream the focus has been on the efforts required to bring the invention forth, and researchers study how new ideas become manifest in future workshops, scenario building, and innovation laboratories (Ehn and Sjögren 1991; Kensing and Madsen 1991). Different techniques to facilitate imaginative leaps and study creativity in describing new artifacts, practices, or narratives have been developed. However, within both of these streams the studies tend to emphasize the break with current solutions, expectations, theories and practices.

We tend to assume that the topic for IS innovation research is the activity of creating something new. However, when we look at our world, we see that the "novel futures" that we seek to design are only one part of the story. Continuity with the past has also played a significant role in historical development. Many of our cities consist of buildings belonging to different historical epochs, and the cities may be organized according to street plans laid out several hundred years ago. Our legal and political systems have ancient roots and elements, and historical aspects also feature strongly in the academe's self-perception. As a research field, we should not only look towards novel futures but also develop our ability to examine, assess, and deal with the durable present. The future will consist not only of new stuff; it will also consist of what we have built and what we are building now. Thus the theme of researching the future should also stimulate us to develop a sensitivity to what will remain from what we do today, and how the elements, fragments, and remnants of the past and of the present will form parts of the future's palimpsest.

The motivation for this emphasis is the observation that we, the human race, are capable of (actively) building and (passively) accumulating more complex technological systems that we can hope to fully understand or manage. Our ability to construct complex socio-technical systems may sometimes seem to outrun our capability to govern them. One example of this is our apparent inability to achieve concerted action to avert massive climate changes. In the next section, I will show how challenges stemming from accumulated complexity are also significant within the field of information systems. Thus my motivation is related to the challenges our organizations and societies face when trying to live with the historically accumulated complexity of digital technologies. In the remainder of the paper, I seek to articulate how we can conceptualize these issues and how our research approaches can become sensitive to them. 


\section{Empirical Motivation: Historical Accumulation of Complexity}

In this section, I will argue that the field of information and communication technology has been strongly shaped by a dynamic where self-induced complexity and remedial action are central. In a retrospective view, we see that major innovations and trends have been spurred by efforts to deal with the emergent consequences, both positive and negative, of previous actions or decisions.

For instance, programmers in the 1960s and 1970s attempted to minimize space and capacity requirements for code, since computer memory and storage was expensive. Saving two digits for every date field was considered a sound engineering trade-off that became best practice. At that time, no one expected programs to live very long: "The near immortality of computer software has come as a shock to programmers. Ask anyone who was there: We never expected this stuff to still be around" (Ullman 1999, p. 126). We then learned that code doesn't evolve; it accumulates (Ullman 1999), and the realization of the potential impact of this "best practice" spurred massive activity in preparation for the year 2000, called by some "the largest concerted repair operation in human history" (Graham and Thrift 2007, p. 12). However, while these activities were enormously costly, they also brought about a boom for the industry and widespread renewal of systems portfolios and creation of new backup, redundancy, and maintenance structures.

This intertwined nature of problems and solutions, of success and trouble, is fundamental to the field. When companies today struggle with the "legacy crisis" (Seacord et al. 2003), one of the reasons is the unexpectedly long-lived and still functioning information systems, an aspect captured by the title of Bennett's (1995) seminal paper on legacy systems: "Coping with Success." However, another reason is the concurrent development of novel solutions to deal with the problems. For instance, when mainframe systems started to age, but could not be easily replaced, middleware technologies emerged. These then offered alternatives to full-blown and dramatic migration, by allowing old legacy systems to be wrapped in newer software (Bennet 1995; Bisbal et al. 1999). While this allowed short-term problem solving, it also contributed to the survival of the legacy systems and thus caused today's heterogeneous systems portfolios. In many companies, multiple platforms, operating systems, programming languages, applications, and user interfaces are intertwined into complex assemblages, which are maintained at enormous costs. A widespread claim is that maintenance costs tend to vary between 65 and 80 percent of an IT departments budget (Webster 2008). In the late 1970s it was already apparent that maintenance, improvements, and adjustments were responsible for the larger part of life-cycle costs (Lienz and Swanson 1981; Lienz et al. 1978). More recently, some studies claim that over 90 percent of total software costs were devoted to maintenance and evolution both in 1990 (Moad 1990) and in 2000 (Erlikh 2000). A significant amount of time (around half) is used to understand the old software, which typically has undocumented and unsystematized code, held together by ad hoc patches and kludges. Another major challenge is caused by interdependencies, as fixes in one part of the system (or in the hosting environment) can have ripple effects in other parts, with cascading errors (Webster 2008). Security suffers in these complex system assemblages, and the demand for integration and interoperability currently constitute vast markets for consultants and solution vendors. 
This accumulated complexity is thus of large practical significance, and currently it strongly shapes the IS practice field. The prime rationale for managerial IT decisions used to be related to arguments about companies' competitive advantage and business agility. However, from practitioners' reports in recent years it may seem that these aspects are overshadowed by the challenges of just coping with IT. IT decisions seem to now be driven by cost considerations and an emphasis on streamlining systems portfolios, reducing complexity and interoperability conflicts, and facilitating manageability. A recent study argued that "software is becoming the limiting factor for progress in all kinds of organizations" (Kalleberg 2007, p. 4). The historically accumulated complexity of information systems has been called "a growing storm on the IT horizon" and a "nightmare of IT staff" that "appears to be approaching the limits of human capability" (Murch 2004).

Historically accumulated complexity also characterizes the situation if we look beyond the organization. Most developed countries struggle with a fragmented digital infrastructure in the public sector. For instance, well-funded, nationally coordinated attempts to standardize information systems and communication in the public health sector have struggled in several countries, including Norway (Hanseth et al. 2006), Denmark (Jensen and Aanestad 2010) and in the United Kingdom, with the NHS's massive National Programme for Information Technology (Currie and Guah 2007; Greenhalgh et al. 2010; Jones 2004). Within e-governance, the preexisting information systems where multiple and incompatible standards are inscribed constitute core obstacles. The complexity associated with this, however, has to do not only with heterogeneous technologies and different organizational structures and cultures. These are also deeply intertwined within an institutionalized "regime" that is upheld by more or less formal regulations of different kinds (Contini and Lanzara 2009). As a result, despite massively funded and nationally coordinated initiatives, widespread interoperability and integration is relatively seldom achieved. Currently, interoperability frameworks and enterprise architectures are the preferred direction of investments (Guijarro 2007; Zachman 1987).

Consequently, it seems that after having digitized the work practice, the organization, and the society, we now have to learn to live with the digital, complex systems assemblages that we have created. This should be a core topic for researchers within the IS field. What are we really doing when we build with information technology? Which futures are we deliberately or inadvertently creating? These are questions that will have great relevance for researching the futures, and the question that I want to develop in the rest of the paper.

\section{Resources for Understanding Durability in Innovation}

In this section, I seek to identify some relevant resources from the literature on general or ICT-specific innovations.

\subsection{Innovation Literature}

Research on innovation has, to a small degree, thematized the durability or continuity of preexisting systems, practices, and understandings. Naturally, the preexisting 
reality is relevant in that it constitutes the basis upon which one builds and from which one simultaneously departs; this is in particular the case for incremental innovations and to a lesser degree for radical innovations. It seems fair to say, however, that in general the preexisting has been conceptualized mainly in the form of barrier and resistance against the new. Since Schumpeter's (1934) emphasis on creative destruction, there seems to have been a stronger interest in the field for radical innovations. For instance, Christensen's (1997) well-known model of disruptive innovations is typical, as it emphasizes how new technologies can surpass the existing, seemingly superior technologies and turn the market landscape upside down.

However, the theme of accumulation, especially of know-how, has been thematized by some researchers. Henderson and Clarke (1990) distinguish between component and architectural innovation, where the latter requires changes (reconfigurations) in the overall scheme of how a solution's components are interrelated. Since the architectural knowledge related to a relatively stable dominant design tends to get embedded into information processes and organizational structures within a firm, established firms may have difficulty reshaping their information processes to fit with architectural innovations. Such conceptualization also has been brought to the study of IT innovations, where significant parts of the innovation process are distributed across heterogeneous networks of actors (Anderson et al. 2008; Boland et al. 2007; Steinmueller 2000; Tuomi 2002).

IT innovations may not follow the traditional manufacturer-oriented and supplypushed innovation patterns, and research has pointed to the role of open and userdriven innovations (Chesbrough et al. 2006; von Hippel 1988). In these networked innovation processes the technology can be both a target and an engine of the innovation (Boland et al. 2007). A crucial challenge for such distributed innovation processes is whether cumulative innovation is actually facilitated; that is, whether intellectual property rights allow or block competitors building on each others achievements and result in collective innovations (Scotchmer 2006). A core observation made by IS innovation scholars is that these innovations will, to a large extent, incorporate existing technologies and reuse parts from existing solutions in new designs within new architectures. Such is the claim by Yoo et al. (2010), who presents a model of the layered modular architecture. Exemplified by the digitization of the book, they describe how devices, networks, services, and content, conceptualized as different layers, are recombined and how the e-book's product architecture changes over time. Such incorporation and reuse of existing solutions will bring a new organizing logic of innovations, demanding new strategic frameworks and new corporate infrastructures. Their model of the layered modular architecture represents insights that are highly relevant contributions for emphasizing the durability of the present. It mobilizes the notion of architecture and components, and thus allows us to thematize interdependencies between components as well as between layers. Such approaches, which allow us to "dis-entangle" rather than black-box the actual innovations, offer possibilities to better grasp the intricate interplay between the existing and the novel in ICT-related innovations. 


\subsection{Innovation in the Context of Evolutionary Technological Change}

Compared with mainstream innovation research, theories of change developed within an evolutionary paradigm seem to be more oriented toward emphasizing the role that the past and the present play in innovations. For instance, Nelson and Winter's (1982) work on an evolutionary theory of technological change describes the stability and conservative effect of existing routines, technologies, etc. Dosi (1982) emphasized the impact by the dominant technological paradigm on innovation processes. He claimed that market forces (i.e., demand) will have a successful impact only within some boundaries defined by the paradigm. This restrictive view on the role of the past also figured in other discourses, evidenced to the focus on path dependency both in historical sociology (Mahoney 2000) and economic theory (David 1985).

Within science and technology studies (STS), we find several relevant historical analyses of technology development in large technical systems (see Summerton 1994). For instance, Thomas Hughes (1983), in his well-known account of the electrification of America, described the constraints shaping the process of network building. From this and other studies, the notion of "installed base" has spread to the IS field. Specifically, it has been taken up in studies of information infrastructure studies. In a seminal study of the evolution of a distributed collaborative system, Star and Ruhleder (1996) formulated key characteristics of information infrastructures. One of them was that "infrastructure does not grow de novo: it wrestles with the inertia of the installed base and inherits strengths and limitations from that base" (Star and Ruhleder 1996, p. 113), a claim that has been further developed and exemplified (Hanseth 2000; Hanseth et al. 1996; Monteiro and Hanseth 1995).

Within the information infrastructure literature, the installed base is seen to offer strengths and opportunities as well as limitations. Its importance is perceived to be so central that "cultivation of the installed base" is proposed as the generic change strategy, replacing traditional planning-oriented and top-down design and development approaches (Ciborra 2000; Hanseth 1996; Hanseth and Lyytinen 2010). Cultivation consists of gradual and incremental extensions, often a long-term process (Heps $\varnothing$ et al. 2009), replacement of elements, utilizing the role of gateways to mitigate conflicts of heterogeneity (David and Bunn 1988; Hanseth, 2001), or to deal with the politicized nature of information infrastructure building (Lyytinen and Damsgaard 2010; Sahay et al. 2009). Thus this stream of research, despite being less innovation-oriented, offers a rich conceptual framework to analyze networked and distributed ICT-related change processes where the existing reality plays a significant role. In particular, the notion of an installed base and the dynamics around it is valuable in this context. Moreover, studies within this stream aim to both encompass the concrete details of their study objects and the larger social and organizational networks of which they are parts, constituting heterogeneous assemblages (Contini and Lanzara 2009), and to explicitly theorize the relations between small and large.

\subsection{Innovation in Practice Studies}

If we turn to empirical, practice-oriented studies of inventions and innovation processes, we will see a close engagement with the existing reality. Studies from the STS field as well as the ethnographically inspired work practice studies within organizational studies (e.g., Gherardi and Nicolini 2000) and within streams such as 
CSCW and PD, all take part in a move of "relocating innovations" (Suchman and Bishop 1999). The achievement (i.e., the innovation) is here conceptualized as socially constructed (i.e., a result achieved through collective work) in situated material practices occurring within distinctive locations. Several laboratory studies described how scientific facts are established, how a certain understanding and mode of working won through, and how innovation activities are deeply enmeshed into a sociotechnically heterogeneous network (Fujimura 1992; Knorr-Cetina 1991; Latour and Woolgar, 1986; Lynch, 1985). Through such an approach, attention is turned toward, not the outcome of the invention or innovation, but the effort and work that goes into producing it. As such, it describes more explicitly the impact of the preexisting technologies, practices, skills, and resources.

It is important to note that this approach, despite the close empirical contact with concrete cases, does not necessarily imply a "situationism," where one is content with studying local achievements and situated interactions (Kallinikos 2002). Many of these studies explicitly address the theme of how the invention or discovery spreads beyond the local situation, and how stabilization and standardization of large-scale collaborative networks are achieved (Bowker and Star 1999; Fujimura, 1992; Ribes and Bowker 2008; Ribes and Finholt 2007, 2009; Star 2002). In the same vein, Latour (2005) emphasized that account of an action or situation that limits itself to the local is insufficient, as there is a lot more to it than local context or situated interactions. "The word interaction was not badly chosen; only the number and type of 'actions' and the span of their 'inter' relationship has been vastly underestimated" (Latour 2005, p. 212). Any action overflows its context; actors far away in space and time have an impact. Action is dislocated, redispatched, and redistributed, and Latour holds that our theories need to encompass the temporal dislocation of present actions, both into the future and in the past.

Although not stemming from the STS discourse, the study of innovation practices by Spinosa et al. (1997) in a similar manner describe how the past is crucial for innovation. Here they discussed which activities and skills go into innovation (termed history-making), and emphasize how the existing is the point of departure that stimulates accumulation, reuse, and recombination. Thus they do not paint a traditional picture of a "heroic innovator" (Sørensen 2008) that identifies a problem or an unmet need and then produces an innovation to solve the problem or fill the need. Rather Spinosa et al. describe practices of working with that which is already present in the situation, and how everyday practices contribute to "historical disclosing" through the practices they name: reconfiguration, cross-appropriation, and articulation. The novelty lies in disclosing, reusing, and interpreting the given and existing in new ways.

These practice studies can contribute to our aim by exemplifying a different take on the empirical object. The practice orientation constitutes a gestalt switch, comparable to what Bowker (1994) called an "infrastructural inversion." To do an infrastructural inversion means that rather than accepting the grand claims about the effects of new technologies, we should "look at the infrastructural changes that preceded or accompanied the effects" (Bowker 1994, p. 235). It is an inquiry driven by uncovering the hidden; we are encouraged to look for the infrastructure this new technology requires, what large hidden system in space and time that has (or will) facilitated its grand, observed (or proclaimed) effects. In the next section, I will argue 
that, in a similar way, when researching IS innovations, we can perform such an infrastructural inversion and approach our study objects differently, from the bottom up.

\section{Studying Durability of the Present}

Initially I argued that researching the future should not only emphasize novelty and discontinuity with the past, but should also recognize the continuity with the existing reality. I argued that a core practical problem in the IS field is the ongoing accumulation of complexity that obstructs organizational as well as interorganizational attempts to realize the benefits of information systems. Another, more positive entry point leading to the same argument is the nature of current IS innovation, and to show how recombinations and reuse of existing and new elements make up innovative products and services. In todays highly dynamic product and service ecologies, novel reconfigurations and combinations of existing elements, as well as additions of new elements are central features. Here, the dynamics between the durable presents and the novel futures are playing out before our eyes, and IS researchers should be able to contribute with adequate and relevant understanding of these dynamics. A solid understanding of the evolution dynamics of the technology would allow the IS field to impact the way our society approaches the tasks of design, construction, and governance of ICTs. In this section, I will offer some opinions on how we could pursue such an understanding.

\subsection{Empirical Objects: Living with Technologies}

Several of our field's constitutive research traditions (such as HCI, CSCW, and ISD) have their roots in design traditions; therefore, the field has developed within a construction or production paradigm. This, I argue, needs to be expanded, and we need to study the reality of living with technologies. When IS researchers during the 1980s started to investigate the phenomena beyond the design and development horizon, such as users' actual usage of systems (Gasser 1986; Kling and Scacchi 1982), or organizational implementation (Keen 1981; Markus 1983), different issues were brought to light and new questions could be asked. Use became a domain that offered novel conceptualizations in its own right. Researchers did not just study use and users in order to offer implications for design, which for a long time was a necessary legitimation of a study (Dourish 2006). Today, the thriving field of implementation studies has given us significantly more insight into the interplay between information and communication technologies and organizations, and a better grasp of what characterizes the technologies.

We may need a similar expansion today with respect to innovation studies and future research. We need to complement the design, development, and innovation orientation of our field with empirical studies of how organizations actually live with the innovative technologies we create. Specifically, I argue, we could perform a gestalt switch, or "infrastructural inversion" (Bowker 1994) and address the actual work of usage, maintenance, upgrading, repairing, caring for, and dismantling systems in organizational and interorganizational contexts. Such an orientation toward maintenance and repair is suggested by Graham and Thrift (2007), and some of the 
same empirical orientation is seen in studies of how technology is made to work (Jewett and Kling 1991), especially in studies of support work (e.g., Orr 1996), thus it is not novel to the field (see also Ciborra 2000).

Such an orientation toward experienced realities can help uncover the way that durability of the present actually plays out. This focus constitutes an infrastructural inversion, a la Bowker, in that it can help us describe the actual work of realization that lies behind the vision, at which cost of maintenance the novel system works, the opportunities it opens, and the ones it closes. Thus we may have a basis from which to estimate the future opportunities, limitations, and costs that we incur in innovative undertakings.

\subsection{Analytic Approach: Focus on Relations and Interdependencies}

Besides choosing other empirical topics, an appropriate analytic take on the issue is required. Here I suggest we turn to Andrew Barry (2001), who has formulated "a different account of invention; one that does not equate technical novelty with inventiveness" (p. 211). He emphasizes the transformative potential of an invention, the opening up of possibilities as its defining aspect. From this perspective,

The notion that technology as something like an isolated artefact is problematic. Technology is viewed not so much as an artefact, but as a series of relations and connections between artefacts, physical and mental skills, desires and interests, concepts and information. Seen in these terms, inventiveness should not be equated with the development of novel artefacts, or indeed with novelty and innovation in general. Rather, inventiveness can be viewed as an index of the degree to which an object or practice is associated with opening up possibilities.... What is inventive is not the novelty of artefacts and devices in themselves, but the novelty of the arrangements with other objects and activities within which artefacts and instruments are situated, and might be situated in the future (Barry 2001, pp. 211-212).

Following Barry, I suggest that the criteria upon which we should assess innovations (or future-generating practices) should consider whether, how, and to what extent they open up possibilities, as well as whether, how, and to what extent they introduce constraints. Our attention should be on the arrangements, the way elements are interrelated. Such an analytic orientation would steer our attention to consider not just the novelty of the specific artifact being designed, but the opportunities and constraints that are introduced when we attempt to reuse, recombine, and accumulate.

This implies that interactions and interdependencies should constitute core targets for our analyses. Which relations are introduced or changed when we recombine elements, or when we add new elements to the existing socio-technical networks? When the set of relations is changed, what implications could it have? Where and for whom will the changes stimulate further innovation; where and for whom will they constitute barriers to growth? In order to investigate such questions, we need theoretical concepts that help us focus on the relationality of socio-technical networks. 


\subsection{Implications for Theory}

We need to go beyond the artifact, device, or system orientation that has been evident in the design-oriented HCI, CSCW, SD, SE, and IS discourses (Tilson et al. 2010). Instead we need to utilize conceptualizations that alert us to relations and connections, to system-level issues related to interactions, couplings, and dependencies. There is a long-standing, but not overly visible, tradition within the IS field that has this orientation. In Orlikowski and Iacono's (2001) literature survey focusing on how the IT artifact was conceptualized, one of their classifications was the "ensemble views," comprising only 12.5 percent of the articles surveyed. An early and prominent example of such an ensemble conceptualization was web models (Kling and Scacchi 1982). The stream of research on information infrastructures (see Hanseth and Lyytinen 2010; Hanseth and Monteiro 1995; Star and Ruhleder 1996; Tilson et al. 2010) has offered significant contributions to understanding large-scale sociotechnical networks. Recent research on digital ecodynamics (El Sawy et al. 2010) and platformcentric eco-systems (Tiwana et al. 2010) approach similar phenomena from different angles. Such theoretical resources would constitute appropriate fundaments for an IS approach that aims to understand and conceptualize the dynamics of technological development.

\section{Final Remarks}

What do we want to be durable? What do we want to end? How can we distinguish between durability that restricts the envisioned and desired futures from becoming realized, versus durability that allows cumulative innovation? How can we build the future with an orientation toward the consequences of today's action? How can we research today's actions with an orientation toward the future?

I have argued that we need an alternative to the common view on the large-scale, digitally interconnected information systems assemblage that we create. We need other studies and other perspectives in order to complement and emphasize the novel. In her study of innovation, Laura Watts $(2009$, p. 3) emphasizes that,

Like the past, the future is made of stuff, of materials, landscapes, and people. Durability and heritage are as much a matter of the future, as a matter of the past. Things endure from past into future. It takes ongoing, unceasing work to conserve, to make things for the world to come.

In her search for a "future archaeology," Watts seeks to create enduring things and bring artifacts into being. Here I wanted to emphasize a related but slightly distinct side of this work to create futures, by arguing that we need to turn our attention to the way our creation has endurance, both in intended and in not intended ways. What we construct today can persist for a long time, either in its original form, or modified and reappropriated in a dynamic digital ecology.

I have suggested that we should perform research investigating the conditions, constraints, and consequences of ICT growth and innovation. In order to do this, studies of the architects and builders (i.e., the designers, developers, managers) should be complemented by studies of repair and maintenance; of the ongoing learning and 
coping activities of all organizational members and technology users. Based on such studies we can improve our understanding of technology development, our capacity for intervention, and the ensuing implications for action. While the traditional innovation orientation exposes research to the dangers of becoming instrumental and uncritical, an approach that is sensitive to the durability of our creations offers a different critical potential for helping us identify the choices we are facing regarding which futures we will create.

\section{References}

Andersson, M., Lindgren, R., Henfridsson, O.: Architectural Knowledge in InterOrganizational IT Innovation. Journal of Strategic Information Systems 17(1), 19-38 (2008)

Barry, A.: Political Machines: Governing a Technological Society. The Athlone Press, Middlesex (2001)

Bennett, K.: Legacy Systems: Coping with Success. IEEE Software 12(1), 19-23 (1995)

Bisbal, J., Lawless, D., Wu, B., Grimson, J.: Legacy Information Systems: Issues and Directions. IEEE Software 16(5), 103-111 (1999)

Boland, R.J., Lyytinen, K., Yoo, Y.: Wakes of Innovation in Project Networks: The Case of Digital 3-D Representations in Architecture, Engineering, and Construction. Organization Science 18(4), 631-647 (2007)

Bowker, G.C.: Science on the Run: Information Management and Industrial Geophysics at Schlumberger, 1920-1940. MIT Press, Cambridge (1994)

Bowker, G.C., Star, S.L.: Sorting Things Out: Classification and its Consequences. MIT Press, Cambridge (1999)

Chesbrough, H., Vanhaverbeke, W., West, J. (eds.): Open Innovation: Researching a New Paradigm. Oxford University Press, Oxford (2006)

Christensen, C.M.: The Innovator's Dilemma: When New Technologies Cause Great Firms to Fail. Harvard Business Press, Boston (1997)

Ciborra, C.: A Critical Review of the Literature on the Management of Corporate Information Infrastructures. In: Ciborra, C., Braa, K., Cordella, A., Dahlbom, B., Failla, A., Hanseth, O., Hespø, V., Ljungberg, J., Monteiro, E., Simon, K.A. (eds.) From Control to Drift-The Dynamics of Corporate Information Infrastructures. Oxford University Press, Oxford (2000)

Contini, F., Lanzara, G.: ICT and Innovation in the Public Sector. Palgrave Macmillan, London (2009)

Currie, W.L., Guah, M.W.: Conflicting Institutional Logics: A National Programme for IT in the Organisational Field of Healthcare. Journal of Information Technology 22(3), 235-247 (2007)

David, P.A.: Clio and the Economics of QWERTY. American Economic Review 75(2), 332-337 (1985)

David, P.A., Bunn, J.A.: The Economics of Gateway Technologies and Network Evolution: Lessons from Electricity Supply History. Information Economics and Policy 3(2), 165-202 (1988)

Dosi, G.: Technological Paradigms and Technological Trajectories: A Suggested Interpretation of the Determinants and Directions of Technical Change. Research Policy 11(3), 147-162 (1982)

Dourish, P.: Implications for Design. In: Proceedings of the SIGCHI Conference on Human Factors in Computing Systems. Montréal, Québec, Canada, pp. 541-550 (2006) 
Ehn, P., Sjögren, P.: From Systems Description to Scripts for Action. In: Greenbaum, J.M., Kyng, M. (eds.) Design at Work: Cooperative Design of Computer Systems, pp. 241-268. Routledge, London (1991)

El Sawy, O.A., Malhotra, A., Park, Y.: Seeking the Configurations of Digital Ecodynamics: It Takes Three to Tango. Information Systems Research 21(4), 835-848 (2010)

Erlikh, L.: Leveraging Legacy System Dollars for E-Business. IEEE IT Pro, May/June 17-23 (2000)

Fichman, R.G.: Going Beyond the Dominant Paradigm for Information Technology Innovation Research: Emerging Concepts and Methods. Journal of the Association for Information Systems 5(8), 314-355 (2004)

Fiol, C.M., O'Connor, E.J.: Waking Up! Mindfulness in the Face of Bandwagons. Academy of Management Review 28(1), 54-70 (2003)

Fujimura, J.: Crafting Science: Standardized Packages, Boundary Objects and "Translations". In: Pickering, A. (ed.) Science as Practice and Culture. University of Chicago Press, Chicago (1992)

Gasser, L.: The Integration of Computing and Routine Work. ACM Transactions on Office Information Systems 4(3), 205-225 (1986)

Gherardi, S., Nicolini, D.: To Transfer is to Transform: The Circulation of Safety Knowledge. Organization 7(3), 329-348 (2000)

Graham, S., Thrift, N.: Out of Order. Understanding Repair and Maintenance. Theory, Culture \& Society 24(3), 1-25 (2007)

Greenhalgh, T., Stramer, K., Bratan, T., Byrne, E., Russell, J., Hinder, S., Potts, H.: The Devil's in The Detail: Final Report of the Independent Evaluation of the Summary Care Record and Healthspace Programmes. University College London, London (2010)

Guijarro, L.: Interoperability Frameworks and Enterprise Architectures in Egovernment Initiatives in Europe and the United States. Government Information Quarterly 24, 89-101 (2007)

Hanseth, O.: Information Infrastructure Development: Cultivating the Installed Base. Studies in the Use of Information Technologies, (16), Department of Informatics, Göteborg University (1996)

Hanseth, O.: The Economics of Standards. In: Ciborra, C., Braa, K., Cordella, A., Dahlbom, B., Failla, A., Hanseth, O., Hespø, V., Ljungberg, J., Monteiro, E., Simon, K.A. (eds.) From Control to Drift-The Dynamics of Corporate Information Infrastructures, pp. 56-70. Oxford University Press, Oxford (2000)

Hanseth, O.: Gateways-Just as Important as Standards: How the Internet Won the "Religious War" Over Standards in Scandinavia. Knowledge, Technology \& Policy 14(3), 71-89 (2001)

Hanseth, O., Lyytinen, K.: Design Theory for Dynamic Complexity in Information Infrastructures: The Case of Building Internet. Journal of Information Technology 25(1), $1-19$ (2010)

Hanseth, O., Monteiro, E.: Social Shaping of Information Infrastructure: On Being Specific About the Technology. In: Orlikowski, W.J., Walsham, G., Jones, M.R., De Gross, J.I. (eds.) Information Technology and Changes in Organizational Work, pp. 325-343. Chapman \& Hall, London (1995)

Hanseth, O., Monteiro, E., Hatling, M.: Developing Information Infrastructure: The tension between Standardization and Flexibility. Science, Technology \& Human Values 21(4), 407-426 (1996) 
Henderson, R.M., Clarke, K.B.: Architectural Innovation: The Reconfiguration of Existing Product Technologies and the Failure of Established Firms. Administrative Science Quarterly 35(1), 9-30 (1990)

Hepsø, V., Monteiro, E., Rolland, K.: Ecologies of eInfrastructures. Journal of the AIS 10(5), 430-446 (2009)

Hughes, T.P.: Networks of Power: Electrification in Western Society, 1880-1930. John Hopkins University Press, Baltimore (1983)

Jensen, T.B., Aanestad, M.: National Initiatives to Build Healthcare Information Infrastructures. In: Proceedings of the MCIS, Paper 43 (2010)

Jewett, T., Kling, R.: The Dynamics of Computerization in a Social Science Research Team: A Case Study of Infrastructures, Strategies and Skills. Social Science Computer Review 9, 246-275 (1991)

Jones, M.: Learning the Lessons of History? Electronic Records in the United Kingdom Acute Hospitals, 1988-2002. Health Informatics Journal 10(4), 253-263 (2004)

Kalleberg, K.T.: Abstractions for Language-Independent Program Transformations. Unpublished Ph.D. thesis, University of Bergen (2007)

Kallinikos, J.: Recalcitrant Technology, Cross-Contextual Systems and Context-Embedded Action. Working Paper Series, (103), London School of Economics (2002)

Keen, P.G.W.: Information Systems and Organizational Change. Communications of the ACM 24(1), 24-33 (1981)

Kensing, F., Madsen, K.H.: Generating Visions: Future Workshops and Metaphorical Design. In: Greenbaum, J.M., Kyng, M. (eds.) Design at Work: Cooperative Design of Computer Systems, pp. 155-168. Routledge, London (1991)

Kling, R., Scacchi, W.: The Web of Computing: Computer Technology as Social Organization. Advances in Computers 21, 1-90 (1982)

Knorr-Cetina, K.: Epistemic Cultures: Forms of Reason in Science. History of Political Economy 23(1), 105-122 (1991)

Latour, B.: Reassembling the Social: An Introduction to Actor-Network Theory. Oxford University Press, New York (2005)

Latour, B., Woolgar, S.: Laboratory Life: The Construction of Scientific Facts. Sage Publications, Beverly Hills (1979)

Lientz, B.P., Swanson, E.B.: Problems in Application Software Maintenance. Communications of the ACM 24(11), 763-769 (1981)

Lientz, B.P., Swanson, E.B., Tompkins, G.E.: Characteristics of Application Software Maintenance. Communications of the ACM 21(6), 466-471 (1978)

Lynch, M.: Art and Artifact in Laboratory Science. Routledge and Kegan Paul, Boston (1985)

Lyytinen, K., Damsgaard, J.: Configuration Analysis of Inter-Organizational Information Systems Adoption. Lecture Notes in Business Information Processing, vol. 60, pp. 127-138 (2010)

Markus, M.L.: Power, Politics, and MIS Implementation. Communications of the ACM 26(6), 430-444 (1983)

Mahoney, J.: Path Dependence in Historical Sociology. Theory and Society 29(4), 507-548 (2000)

Moad, J.: Maintaining the Competitive Edge. Datamation, 61-62 (1990)

Monteiro, E., Hanseth, O.: Social Shaping of Information Infrastructure: On Being Specific About Technology. In: Orlikowski, W.J., Walsham, G., Jones, M.R., DeGross, J.I. (eds.) Information Technology and Changes in Organizational Work, pp. 325-343. Chapman \& Hall, London (1995)

Murch, R.: Autonomic Computing. IBM Press, Armonk (2004) 
Nelson, R.R., Winter, S.G.: An Evolutionary Theory of Economic Change. Harvard University Press, Boston (1982)

Orlikowski, W.J., Iacono, C.S.: Research Commentary: Desperately Seeking the "IT" in IT Research-A Call to Theorizing the IT Artifact. Information Systems Research 12(2), 121-134 (2001)

Orr, J.E.: About Machines. An Ethnography of a Modern Job. ILR Press, Ithaca (1996)

Ribes, D., Bowker, G.: Organizing for Multidisciplinary Collaboration: The Case of the Geosciences Network. In: Olson, G.M., Zimmerman, A., Bos, N. (eds.) Scientific Collaboration on the Internet. MIT Press, Cambridge (2008)

Ribes, D., Finholt, T.: Tensions Across the Scales: Planning Infrastructure for the Long-Term. In: Proceedings of the 2007 International ACM Conference on Supporting Group Work, pp. 229-238 (2007)

Ribes, D., Finholt, T.: The Long Now of Information Infrastructures. Articulating Tensions in Development. Journal of the AIS 10(5), 375-398 (2009)

Risan, L.: The Duration of the Present and the Risk of Not Telling Large Stories. EASST Review (October 2006), http: / /www. easst. net/review/oct2006/risan

Sahay, S., Monteiro, E., Aanestad, M.: Configurable Politics and Asymmetric Integration: Health e-Infrastructures in India. Journal of the AIS 10(5), 399-414 (2009)

Schumpter, J.: The Theory of Economic Development. Harvard University Press, Cambridge (1934)

Scotchmer, S.: Innovation and Incentives. MIT Press, Cambridge (2006)

Seacord, R., Plakosh, D., Lewis, G.: Modernizing Legacy Systems: Software Technologies, Engineering Processes, and Business Practices. Addison-Wesley, Reading (2003)

Spinosa, C., Flores, F., Dreyfus, H.: Disclosing New Worlds: Entrepreneurship, Democratic Action and the Cultivation of Solidarity. MIT Press, Cambridge (1997)

Sørensen, B.M.: Behold, I Am Making All Things New: The Entrepreneur as Savior in the Age of Creativity. Scandinavian Journal of Management 24(2), 85-93 (2008)

Star, S.L.: Infrastructure and Ethnographic Practice: Working on the Fringes. Scandinavian Journal of Information Systems 14(2), 107-122 (2002)

Star, S.L., Ruhleder, K.: Steps Toward an Ecology of Infrastructure: Design and Access for Large Information Spaces. Information Systems Research 7(1), 111-134 (1996)

Steinmueller, E.: Does Information and Communication Technology Facilitate Codification of Knowledge? Industrial and Corporate Change 9, 361-476 (2000)

Suchman, L., and Bishop, L.: Problematizing Innovation as a Critical Project. Paper presented in the panel Critical Potential of Innovation Studies, Conference on Critical Management Studies, Manchester, England (1999)

Summerton, J. (ed.): Changing Large Technical Systems. Westview, Boulder (1994)

Swanson, E.B., Ramiller, N.: Innovating Mindfully with Information Technology. MIS Quarterly 28(4), 553-583 (2004)

Tilson, D., Lyytinen, K., Sørensen, C.: Digital Infrastructures: The Missing IS Research Agenda. Information Systems Research 21(4), 748-759 (2010)

Tiwana, A., Konsynski, B., Bush, A.A.: Platform Evolution: Coevolution of Platform Architecture, Governance, and Environmental Dynamics. Information Systems Research 21(4), 675-687 (2010)

Tuomi, I.: Networks of Innovation: Change and Meaning in the Age of the Internet. Oxford University Press, New York (2002)

Ullman, E.: The Myth of Order. WIRED, Issue 7.04 (April 1999)

von Hippel, E.: The Sources of Innovation. Oxford University Press, New York (1988) 
Watts, L.: Future Archeologies. Method and Story, Keynote address given at the Society of Museum Archaeologists Conference, Guildhall, Winchester UK (November 5, 2009), http://eprints.lancs.ac.uk/31783/1/ watts_futurearchaeologies.pdf

Webster, B.: Surviving Complexity. Baseline Magazine (2008)

Yoo, Y., Henfridsson, O., Lyytinen, K.: The New Organizing Logic of Digital Innovation: An Agenda for Information Systems Research. Information Systems Research 21(4), 724-735 (2010)

Zachman, J.: A Framework for Information Systems Architecture. IBM Systems Journal 26(3), $276(1987)$

\section{About the Author}

Margunn Aanestad is an associate professor of Information Systems in the Department of Informatics, University of Oslo, Norway. She is interested in understanding the interaction between technical, social, organizational, and regulatory elements in the development of large-scale information infrastructures, and has studied ICTs in healthcare, both in developed and developing countries. Her research has been published in Journal of Information Technology, MIS Quarterly, European Journal of Information Systems, Journal of the Association for Information Systems, and other journals. 